\title{
EMPLEADOR ÚNICO (UNIDAD ECONÓMICA): REQUISITOS DE CONFIGURACIÓN, ALCANCE DE LA EXIGENCIA DIRECCIÓN LABORAL COMÚN Y PROCEDENCIA DE LA ACCIÓN DE SUBTERFUGIO. COMENTARIO A LA SENTENCIA DE NULIDAD DE LA CORTE DE APELACIONES DE CONCEPCIÓN, ROL REFORMA LABORAL N ${ }^{\circ} 76-2015$
}

\author{
SINGLE EMPLOYER (ECONOMIC UNIT): CONFIGURATION \\ REQUIREMENTS. SCOPE OF THE COMMON WORK ADDRESS \\ EXIGENCY AND PROVENANCE OF THE SUBTERFUGE \\ ACTION. COMMENTARY ON THE REVOCATION OF \\ JUDGMENT OF THE COURT OF APPEALS OF CONCEPCIÓN, \\ ROLE LABOR REFORM NO. 76-2015
}

\author{
Raúl Fernández Toledo* \\ Universidad de Chile
}

\section{GENERALIDADES}

Hasta el mes de julio de 2014 se aceptaba en nuestro país la unidad económica, esto es, que dos o más empresas fueran declaradas como un solo empleador para efectos laborales, fundado en principios propios del Derecho del Trabajo, especialmente el principio de la primacía de la realidad. La unidad económica era hasta ese entonces una creación jurisprudencial, desde que no se encontraba regulada en la legislación laboral. Es por ello que a fin de otorgar seguridad jurídica se decidió regular legalmente la unidad económica bajo la expresión de "un solo empleador" o "empleador común", como también se le denomina. Lo que se materializó a través de la Ley $\mathrm{N}^{\circ}$ 20.760 publicada en el Diario Oficial el 9 de julio de 2014, que modificó el inciso $3^{\circ}$ del artículo 3 del Código del Trabajo, que define la empresa para efectos laborales y de seguridad social, y agregó los incisos $4^{\circ}, 5^{\circ}, 6^{\circ}, 7^{\circ}$ y $8^{\circ}$ al mismo precepto, además, de reemplazar íntegramente el artículo 507 del Código del Trabajo ${ }^{1}$.

Abogado. Licenciado en Ciencias Jurídicas y Sociales, Universidad de Concepción. Magíster en Derecho del Trabajo y de la Seguridad Social, Universidad de Talca - Universidad de Valencia. Instructor del Departamento de Derecho del Trabajo y de la Seguridad Social, Facultad de Derecho, Universidad de Chile. Contacto: rfernandez@uchile.derecho.cl

1 Véase un tratamiento detallado de la regulación del empleador común en el Código del Trabajo, López (2015) pp. 79-104. 
Raúl Fernández Toledo / Empleador único (unidad económica): requisitos de configuración, alcance de la exigencia dirección laboral común y procedencia de la acción de subterfugio. Comentario a la sentencia de nulidad de la Corte de Apelaciones de Concepción Rol Reforma Laboral $N^{\circ} 76-2015$

Es así, como actualmente se encuentran establecidos en el Código del Trabajo los requisitos que son necesarios para que dos o más empresas sean declaradas como empleador común y las consecuencias jurídicas que derivan de dicha declaración. Sin embargo, las nuevas disposiciones legales pueden presentar dificultades en su interpretación y aplicación, pudiendo generar opiniones divergentes en los tribunales de justicia, que son quienes tienen la competencia para declarar como un solo empleador a dos o más empresas. De ahí, la importancia de determinar su correcto sentido y alcance, labor que deben efectuar la doctrina y jurisprudencia.

A través del presente comentario de jurisprudencia se analizan los requisitos que son necesarios para que dos o más empresas sean declaradas empleador común ${ }^{2}$, el alcance del requisito de dirección laboral común y la conexión entre la acción de declaración de empleador común y la acción de subterfugio. En otros términos, se analizarán las razones del por qué en concepto de la Corte de Apelaciones de Concepción no se configuró la unidad económica y el subterfugio bajo los nuevos artículos 3 y 507 del Código del Trabajo que fueron complementados y reemplazados respectivamente por la Ley $\mathrm{N}^{\circ} 20.760$, conocida como "Ley del Multirut".

\section{ANTECEDENTES DEL CASO}

En el proceso en que recayó la sentencia de la Corte de Apelaciones de Concepción se discutió la procedencia de la indemnización de perjuicios por accidente del trabajo, la figura del co - empleador y de la unidad económica, siendo el demandante un trabajador y los demandados dos sociedades de responsabilidad limitada y una persona natural ${ }^{3}$. Se solicitó por el trabajador que se declarara que la Sociedad Conformadora de Aceros Chile Limitada y don Rubén Isaac Gatica Romero son sus co - empleadores, y que la Sociedad Conformadora de Aceros Chile Limitada y Conformadora de Aceros Limitada constituyen una unidad económica, debiendo responder los demandados como consecuencia de ello solidariamente de la indemnizaciones de perjuicios derivadas del accidente del trabajo que sufrió. También, el demandante alegó subterfugio y simulación laboral.

Los demandados contestaron en tiempo y forma la demanda, negando los hechos señalados por el demandante, entre ellos, los que constituyen la causa de pedir de las acciones destinadas a ser declarados empleadores comunes. De este modo, uno de los puntos centrales de la controversia del juicio consistió en determinar si los demandados constituyen un solo empleador y si existió simulación o subterfugio, fijándose por el juez a quo en la audiencia preparatoria luego de recibirse la causa a prueba dos hechos controvertidos a ser probados en ese sentido.

Los hechos que se establecieron en la sentencia definitiva respecto de la situación de los demandados son los siguientes: Conformadora de Aceros Limitada tiene como representante legal a don Rubén Isaac Gatica Romero, domicilio en calle Los Castaños $\mathrm{N}^{\circ} 325$, comuna de Chiguayante, su actividad económica es industrias básicas de hierro y acero, no tiene trabajadores, no mantiene libro de remuneraciones ni cuenta con recursos humanos. Por su parte, la Sociedad Conformadora de Aceros Chile también tiene como representante legal a don Rubén Isaac Gatica Romero, su domicilio igualmente está en calle Los Castaños $\mathrm{N}^{\circ} 325$, comuna de Chiguayante, su actividad económica es la fabricación de otros productos elaborados de Metal N.C.P. y ventas al por mayor de otros productos N.C.P.; tiene 15 trabajadores, entre ellos, el trabajador demandante. Don Rubén Isaac Gatica Romero tiene domicilio en calle Los Castaños No 365 , comuna de Chi-

Las expresiones unidad económica, empleador común y un solo empleador se emplearán indistintamente, considerándose sinónimas en el presente comentario de jurisprudencia.

3 Existió una pluralidad de partes demandadas. 
guayante, es persona natural sin giro ni iniciación de actividades, tiene solamente un trabajador para cuidar una parcela de agrado.

Asimismo, se determinó que Conformadora Aceros Limitada y Sociedad Conformadora de Aceros Chile Limitada funcionaron simultáneamente durante los años 2001 y 2003, siendo traspasados en este último año la totalidad de trabajadores dependientes de Conformadora Aceros Limitada a Sociedad Conformadora de Aceros Chile Limitada. En cuanto a la imagen corporativa, corresponde al logo de la Sociedad Conformadora de Aceros Chile Limitada, el cual aparece en los documentos oficiales y en la página web de la empresa.

Finalmente, la sentencia definitiva determinó que el trabajador demandante sufrió un accidente del trabajo que le ocasionó daño moral imputable a su empleador Sociedad Conformadora de Aceros Chile Limitada, condenando pagar a esta empresa $\$ 20.000 .000$, con intereses y reajustes por concepto de daño moral, y rechazó las acciones de unidad económica, de co - empleador, de subterfugio y de simulación, por no estimarlas configuradas.

La empresa Sociedad Conformadora de Aceros Chile Limitada interpuso recurso de nulidad fundado en la causal del artículo 478 letra b) del Código del Trabajo y, en subsidio, en la causal del artículo 477 inciso $1^{\circ}$ del mismo Código (infracción de ley), con el propósito de alterar la decisión del tribunal de la instancia sobre la condena de indemnización por concepto de daño moral. Por su parte, el trabajador demandante interpuso recurso de nulidad fundado en la causal del artículo 478 letra b) del Código del Trabajo y, subsidio, en la causal del artículo 478 letra e) del Código del Trabajo, con el fin que se alterara la decisión que rechazó la declaración de un sólo empleador. Ambos recursos fueron rechazados por la Corte de Apelaciones de Concepción, por estimar que no se configuraron las causales de nulidad invocadas por los recurrentes.

Según se indicó, en el presente comentario de jurisprudencia se expondrán las razones por las cuales la Corte rechazó el recurso de nulidad del demandante, confirmando la decisión del Juzgado de Letras del Trabajo de Concepción que rechazó la declaración de empleador único. Es decir, se analizarán las razones de por qué se estimó que las demandadas no eran empleador común ni incurrieron en subterfugio a la luz de lo dispuesto en los artículos 3 inciso $4^{\circ}$ y 507 respectivamente del Código del Trabajo, incorporados por la Ley $\mathrm{N}^{\circ} 20.760$.

\section{ANÁLISIS DE LA DECISIÓN DE LA CORTE DE APELACIONES DE CONCEPCIÓN SOBRE LA UNIDAD ECONÓMICA}

La Corte de Apelaciones de Concepción para rechazar el recurso de nulidad interpuesto por el trabajador demandante determina que no concurren los requisitos configuradores de la unidad económica y tampoco del subterfugio. Decisión que realiza al amparo de lo dispuesto en los artículos 3 inciso $4^{\circ}$ y 507 del Código del Trabajo, incorporados por la Ley $\mathrm{N}^{\circ} 20.760$.

\subsection{REQUiSITOS PARA LA CONFIGURACIÓN DE LA UNIDAD ECONÓMICA O EMPLEADOR ÚNICO}

Lo primero que examina la Corte de Apelaciones de Concepción son los requisitos que deben concurrir para que dos o más empresas sean consideradas un solo empleador conforme a lo 
Raúl Fernández Toledo / Empleador tínico (unidad económica): requisitos de configuración alcance de la exigencia dirección laboral comín y procedencia de la acción de subterfugio. Comentario a la sentencia de nulidad de la Corte de Apelaciomes de Concepción Rol Reforma Laboral $N^{\circ} 76-2015$

dispuesto en el artículo 3 inciso $4^{\circ}$ del Código del Trabajo ${ }^{4}$. Señala la Corte que es necesario para la declaración de empleador común de dos o más empresas los siguientes requisitos:

a) Dirección laboral común; y

b) Concurran a su vez otras condiciones, tales como, similitud o complementariedad de los productos o servicios que elaboren o presten, o la existencia entre ellas de un controlador común ${ }^{5}$.

Agrega el tribunal superior penquista que "el elemento fundamental es la existencia de una dirección laboral común, el cual no puede faltar, aunque las otras condiciones sean diferentes a las mencionadas a título de ejemplo en la norma en comento"6.

Según se puede observar, para la Corte junto al requisito de la dirección laboral común necesariamente deben concurrir algunas otras de las condiciones enumeradas en el artículo 3 inciso $4^{\circ}$ luego de la conjunción copulativa " $y$ " $u$ otras condiciones similares, no bastando solamente con la concurrencia de la dirección laboral común, no obstante ser la existencia fundamental. Lo que demuestra que la dirección laboral común debe siempre debe estar presente junto a otras condiciones, que no necesariamente son las enumeradas en el artículo 3 inciso $4^{\circ}$ del Código del Trabajo. Es así, como se está ante la presencia de requisitos que deben concurrir en forma copulativa, por lo que si falta uno de ellos o ambos no podrá determinarse que dos o más empresas son un solo empleador.

Conclusión que resulta correcta, en nuestra opinión, debido a que si el legislador hubiese exigido única y exclusivamente la concurrencia de la dirección laboral común para que dos o más empresas fueran declaradas como empleador común habría bastado con incorporar en el inciso $4^{\circ}$ del artículo 3 del Código del Trabajo solamente la siguiente frase: "dos o más empresa serán consideradas como un solo empleador para efectos laborales y previsionales cuando tengan una dirección laboral común", habiendo sido inútil agregar la frase: " $y$ concurran a su respecto condiciones tales como la similitud y necesaria complementariedad de los productos o servicios que elaboren o presten, o la existencia entre ellas de un controlador común". Si la Ley $\mathrm{N}^{\circ} 20.760$ decidió incorporar en el artículo 3 inciso $4^{\circ}$ ambas frases conjuntamente unidas bajo la conjunción copulativa " $y$ " fue precisamente porque exige que para estar en presencia del empleador común debe concurrir la dirección laboral común y otras condiciones como las que enumera u otras, de lo contrario, no se justifica la segunda parte del párrafo luego de la conjunción " $y$ ".

Para llegar a esta conclusión basta recurrir al elemento gramatical de interpretación de la ley consagrado en el artículo 19 inciso $1^{\circ}$ del Código Civil, que es el primer elemento de interpretación a que debe recurrirse para interpretar la ley. No es necesario acudir a otros elementos de interpretación de la ley, debido a que el sentido del artículo 3 inciso $4^{\circ}$ del Código del Trabajo emana claramente de su tenor literal, no pudiendo desatenderse a pretexto de consultar su espíritu, tal como lo ordena el artículo 19 inciso $1^{\circ}$ del Código Civil.

Debe precisarse que no es unánime el criterio que el artículo 3 inciso $4^{\circ}$ consagra dos requisitos copulativos. Es así, como la Dirección del Trabajo sostiene que "no se trata de requisitos copulativos, de tal modo que la dirección laboral común, el elemento determinante, puede ver-

\footnotetext{
4 Dispone el artículo 3 inciso $4^{\circ}$ del Código del Trabajo: "Dos o más empresas serán consideradas como un solo empleador para efectos laborales y previsionales, cuando tengan una dirección laboral común, y concurran a su respecto condiciones tales como la similitud o necesaria complementariedad de los productos o servicios que elaboren o presten, o la existencia entre ellas de un controlador común".

5 Considerando $10^{\circ}$ de la sentencia comentada.

6 Considerando $10^{\circ}$ de la sentencia comentada.
} 
Raúl Fernández Toledo / Empleador único (unidad económica): requisitos de configuración, alcance de la exigencia dirección laboral comín y procedencia de la acción de subterfugio. Comentario a la sentencia de nulidad de la Corte de Apelaciones de Concepción, Rol Reforma Laboral $N^{\circ} 76-2015$

se reforzado mediante la concurrencia de alguno de los elementos indiciarios contenidos en la norma o a través de otros indicios" ${ }^{\prime \prime}$. Para sustentar su posición recurre a la historia de la Ley $\mathrm{N}^{\circ}$ 20.670, a una opinión de la Ministra del Trabajo en sesión de la Comisión de Trabajo y Previsión del Senado de fecha 7 de mayo de 2014, quien sostuvo "que los requisitos no son copulativos y lo esencial y definitivo que siempre debe estar es la identificación de la dirección laboral común, cuyo concepto dice relación con el vínculo de subordinación, con quien manda o dirige una unidad económica y toma decisiones de contratación y despido"8.

Misma opinión que defiende un sector de la doctrina, para la cual la similitud o complementariedad de los giros de las empresas o la existencia de un mismo controlador $u$ otras condiciones similares son solamente indicios de la concurrencia del requisito dirección laboral común, que es el único requisito que debe verificarse para la declaración de empleador común ${ }^{9}$.

No compartimos la opinión de la Dirección del Trabajo y de un sector de la doctrina nacional por las razones expuestas anteriormente. Además, no procede recurrir a la historia de la ley cuando el sentido de la ley es claro. El elemento histórico solamente tiene lugar cuando la ley es obscura ${ }^{10}$, característica que no tiene el artículo 3 inciso $4^{\circ}$ del Código del Trabajo. Sostener lo contrario, sería pasar por alto el sistema de interpretación de la ley establecido con carácter general en el Código Civil, desconociendo abiertamente el sentido y alcance del inciso $4^{\circ}$ del artículo 3 del Código del Trabajo. El intérprete no puede dar por establecido aquello que la ley no señala ni crear una ley nueva, desde que esa no es su función, sino determinar el correcto sentido y alcance de la ley interpretada.

\subsection{SENTIdo y ALCANCE DEL REQUisito DiRECCión LABORAL COMÚN}

La Corte de Apelaciones de Concepción deja en claro que el requisito principal que debe concurrir y acreditarse para la declaración de empleador común es la "dirección laboral común", fijando su concepto de acuerdo a pronunciamientos de la Dirección del Trabajo. Señala que:

"La Dirección del Trabajo ha definido el poder de dirección laboral como una serie de facultades o prerrogativas que tienen por objeto el logro del referido proyecto empresarial en lo que al ámbito laboral se refiere, y que se traducen en la libertad para contratar trabajadores, ordenar las prestaciones laborales, adaptarse a las necesidades del mercado, controlar el

\footnotetext{
Dirección del Trabajo. Ord. N $^{\circ}$ 3406/054, de 3 de septiembre de 2014, disponible en http://www.dt.gob.cl/legislacion/1611/ w3-article-103870.html [consultada el 4 de mayo de 2015]

8 Historia de la Ley $\mathrm{N}^{\circ} 20.760$, de 2014, p. 388, disponible en http://www.leychile.cl/Consulta/portada_hl?tipo_ norma $=X X 1 \&$ nro_ley $=20760 \&$ anio $=2015$ [consultada el 4 de mayo de 2015]

LóPEZ (2015) pp. 89-90.

10 Alessandri, Arturo et. al. (2011) p. 187: "El elemento lógico y el histórico están contemplados en el inciso $2^{\circ}$ del artículo $19 \mathrm{y}$ en el inciso $1^{\circ}$ del artículo 22 [...]. Una expresión es oscura cuando no puede entenderse absolutamente (ininteligible) o cuando se presta a dos o más interpretaciones (ambigua). Es muy difícil, casi imposible, que la primera situación se presente, dado el gran número de personas que interviene en la formación y aprobación de las leyes; la segunda por el contrario, se halla con frecuencia [...]. Sería sacrificar el fondo por la forma, si por el solo hecho de existir expresiones ininteligibles o ambiguas, la ley no se aplicara o se aplicara mal; si a pesar de aquellos vicios, el espíritu de la ley se manifiesta claramente, sea en el propio artículo que contiene lo ambiguo o lo ininteligible, sea en cualquiera otro de la misma ley, debe ésta imponerse de acuerdo con ese espíritu".
} 
Raúl Fernández Toledo / Empleador único (unidad económica): requisitos de confrguración, alcance de la exigencia dirección laboral común y procedencia de la acción de subterfugio. Comentario a la sentencia de nulidad de la Corte de Apelaciones de Concepción, Rol Reforma Laboral $N^{\circ} 76-2015$

cumplimiento y ejecución del trabajo convenido y, sancionar las faltas o los incumplimientos contractuales del trabajador"11.

\section{Y agrega:}

"Por su parte, dirección laboral común será en consecuencia, cuando estas facultades o prerrogativas están más o menos compartidas o coordinadas, en diversas empresas, relacionadas por un vínculo de propiedad. No resultando suficiente el sólo vínculo propietario, toda vez que debe existir el ejercicio conjunto de la potestad de mando laboral en relación a los dependientes de las empresas vinculadas (Ordinario No2856/162, de 30.08.2002 y No3406/054 de 03.09.2014)"12.

En lo expuesto no existe mayor novedad, debido a que reitera lo sostenido al respecto por la Dirección del Trabajo, pero en lo que sí innova es que precisa que la dirección laboral común debe darse respecto de trabajadores contratados formalmente por diversas empresas, para lo cual sostiene que "puede agregarse que la dirección laboral común importa la existencia de instrucciones impartidas por una jefatura única o que éstas son iguales para todos los trabajadores, a pesar de estar contratados por sociedades diversas. Sin ello no es posible considerar a las empresas como un solo empleador"13.

$\mathrm{Si}$ algunas de las empresa demandadas no tiene trabajadores dependientes no puede ser declara como empleador único con las empresas que sí tienen trabajadores, toda vez que no podrá hablarse de dirección laboral común respecto de aquellas empresas, al carecer de trabajadores respecto de los cuales ejercer dicha dirección. Solamente puede hablarse de dirección laboral común cuando todas las empresas demandadas tienen trabajadores dependientes y las instrucciones se imparten indistintamente por una misma jefatura a todos esos trabajadores.

La Corte establece que una de las empresa demandadas no tiene trabajadores dependientes y que la persona natural demandada no tiene inicio de actividades, por lo que concluye que "los antecedentes expuestos no permiten acreditar la existencia de instrucciones impartidas por una jefatura única o que éstas son iguales para todos los trabajadores, a pesar de estar contratados por sociedades diversas, por cuanto una de las demandadas no tiene trabajadores ni cuenta con procesos productivos vigentes"14. Es así, que la Corte penquista determina que no concurre la dirección laboral común porque solamente una de las empresas demandadas tiene trabajadores, lo que obsta a la configuración de dicho requisito.

La conclusión resulta acertada, desde que no puede hablarse de dirección laboral común en varias empresas cuando algunas de ellas no tienen trabajadores dependientes, que es el presupuesto esencial para establecer si existe dirección laboral común. Por tanto, frente a una acción de declaración de empleador común ejercida en contra dos o más empresas lo primero que debe establecer el juez a quo es si las empresas tienen o no trabajadores dependientes. Si no tienen trabajadores dependientes, basta esa sola circunstancia para rechazar la acción de empleador común

\footnotetext{
11 Considerando $11^{\circ}$ de la sentencia comentada.

12 Considerando $11^{\circ}$ de la sentencia comentada.

13 Considerando $11^{\circ}$ de la sentencia comentada.

14 Considerando $24^{\circ}$ de la sentencia comentada.
} 
Raúl Fernández Toledo / Empleador único (unidad económica): requisitos de configuración, alcance de la exigencia dirección laboral común y procedencia de la acción de subterfugio. Comentario a la sentencia de nulidad de la Corte de Apelaciones de Concepción, Rol Reforma Laboral $N^{\circ} 76-2015$

respecto de las empresas que carecen de trabajadores. Por el contrario, si tienen trabajadores dependientes, debe examinarse luego si tienen los mismos una dirección laboral común.

Esta precisión tiene consecuencias prácticas, debido a que las empresas de inversión no podrán ser declaradas como empleador único junto a otras empresas, por carecer generalmente de trabajadores dependientes, aun cuando los propietarios sean los mismos sujetos, debido a que el artículo 3 inciso $5^{\circ}$ del Código del Trabajo deja en claro que: "La mera circunstancia de participación en la propiedad de las empresas no configura por sí sola alguno de los elementos o condiciones señalados en el inciso anterior". Por tanto, no resulta procedente ejercer en contra de las empresas de inversión que no tienen trabajadores dependientes la acción de declaración de empleador único, y si de todas formas se ejerce, debe rechazarse dicha acción por no concurrir uno de sus elementos configuradores.

\subsection{ACCIÓN DE SUbTERfugio LABORAL ACCESORIA DE LA ACCIÓN DECLARATIVA DE EMPLEADOR COMÚN}

Se rechaza por la Corte de Apelaciones de Concepción la acción de subterfugio laboral debido a que se concluye que procede únicamente cuando se declara previamente que dos o más empresas son un solo empleador, siendo "su consecuencia exclusivamente la aplicación de una multa de 20 a 300 UTM y no el pago de las obligaciones laborales"15. De este modo, actualmente no procede ejercerse la acción ni declararse el subterfugio independientemente del empleador común, porque tal como concluye la Corte de Apelaciones de Concepción "la figura del subterfugio independiente de la declaración del acogimiento de la acción del artículo 3 inciso $4^{\circ}$ del Código del Trabajo no existe"16. Conclusión que resulta ajustada a derecho luego de las modificaciones introducidas por la Ley $\mathrm{N}^{\circ} 20.760$ al Código del Trabajo.

La Ley $\mathrm{N}^{\circ} 20.760$ eliminó completamente el artículo 507 del Código del Trabajo, que regulaba las acciones de subterfugio y de simulación laboral como acciones principales e independientes, en virtud de las cuales se podía declarar que dos o más empresas fueran declaradas como un solo empleador. Es así, que en la práctica, antes de la vigencia de la ley señalada, se ejercía la acción de unidad económica o bien la acción de subterfugio o de simulación con el propósito que dos o más empresas fueran declarados como un solo empleador. Producto de las modificaciones de la Ley $\mathrm{N}^{\circ} 20.760$, que reemplazó íntegramente el artículo 507, la situación es totalmente diferente, toda vez que las acciones de subterfugio y de simulación no pueden ejercerse autónomamente, sino solamente a consecuencia del ejercicio de la acción de empleador común prevista en el artículo 3 inciso $4^{\circ}$ y siguientes del Código del Trabajo. El tenor literal del nuevo artículo 507 comprueba esta conclusión al sostener: que

"Las acciones judiciales derivadas de la aplicación del inciso cuarto del artículo $3^{\circ}$ de este Código podrán ser ejercidas por las organizaciones sindicales o trabajadores de las respectivas empresas que consideren que sus derechos laborales o previsionales han sido afectados [...]. La sentencia definitiva que dé lugar total o parcialmente a las acciones entabladas deberá contener en su parte resolutiva: [...] 3. La determinación acerca de si la alteración de la individualidad del empleador se debe o no a la simulación de contratación de trabajadores a través de

15 Considerando $24^{\circ}$ de la sentencia comentada. 
Raúl Fernández Toledo / Empleador único (unidad económica): requisitos de configuración alcance de la exigencia dirección laboral comín y procedencia de la acción de subterfugio. Comentario a la sentencia de nulidad de la Corte de Apelaciones de Concepción, Rol Reforma Laboral $N^{\circ} 76-2015$

terceros, o bien a la utilización de cualquier subterfugio, ocultando, disfrazando o alterando su individualización o patrimonio, y si ello ha tenido como resultado eludir el cumplimiento de las obligaciones laborales y previsionales que establece la ley o la convención. Si así lo determina, deberá señalar de manera precisa las conductas que constituyen dicha simulación o subterfugio y los derechos laborales y previsionales que por esta vía se hubieren vulnerado, debiendo aplicar al infractor una multa de 20 a 300 unidades tributarias mensuales. En estos casos, será aplicable a las multas señaladas lo dispuesto en el inciso quinto del artículo 506 de este Código".

Si se examina el artículo 507 del Código del Trabajo el único efecto que tiene la declaración de subterfugio es la aplicación de una multa a las empresas que han incurrido en dicho ilícito laboral, ninguna otra consecuencia jurídica. Las principales consecuencias jurídicas el legislador las reservó para la declaración de empleador común.

La acción de subterfugio es prejudicial a la acción de empleador único, debido a que para que sea resuelta es necesario que se emita un pronunciamiento favorable sobre la acción de empleador único ${ }^{17}$. También es accesoria, al ser subordinada y dependiente a la acción de declaración de empleador único ${ }^{18}$. Lo que trae como consecuencia práctica que debe ejercerse conjuntamente con la acción de empleador común y que si se rechaza esta acción se rechaza también la acción de subterfugio por esa sola circunstancia. Por el contrario, si se acoge la acción de declaración de empleador común debe examinarse si las empresas demandadas incurrieron en subterfugio, de haberse ejercido esta acción por la parte trabajadora ${ }^{19}$.

\section{CONCLUSIONES}

La sentencia dictada por la Corte de Apelaciones de Concepción resulta totalmente ajustada a derecho al concluir que dos son los requisitos copulativos que deben concurrir para acoger la acción de empleador común, cuales son la dirección laboral común y otras condiciones enumeradas en el artículo 3 inciso $4^{\circ}$ del Código del Trabajo u otras similares. También son acertadas las conclusiones de la Corte en orden a que no existe dirección laboral común si sólo una de las empresas demandadas tiene trabajadores dependientes y que la acción de subterfugio no se configura en forma independiente a la acción de empleador único.

\footnotetext{
$17 \quad$ El profesor Romero señala: "Una acción es prejudicial de otra cuando para que ella sea resuelta necesita que se emita un pronunciamiento anterior sobre otra acción". Romero (2007) p. 80.

is Romero (2007) p. 80: “5. La accesoriedad. Ella se da cuando entre dos acciones una de las cuales se llama precisamente accesoria, una aparece como subordinada y dependiente por el título de la otra (que se denomina principal)".

19 No somos de la opinión que los tribunales de justicia pueden de oficio entrar a establecer si las empresas demandadas incurrieron en subterfugio o simulación cuando la parte trabajadora solamente ejerció la acción de declaración de empleador común y no ejerció alguna de aquellas acciones. En el proceso laboral rige el principio dispositivo, el cual impone a las partes como carga procesal introducir al proceso los hechos, las acciones y excepciones que desean sean conocidas por el juez el trabajo, debiendo el juez dictar su sentencia definitiva conforme a esos hechos acreditados en el proceso, las acciones alegadas y las excepciones opuestas. Véase sobre el principio dispositivo en el proceso laboral: Fernández (2011) pp. 37 - 53.
} 